\title{
Effects of Circuit Training and Battle Rope Training on Upper Body Muscular Endurance
} of School Girls

\author{
Dr. Maniazhagu Dharuman ${ }^{1}$, Dr. N.V. Thiyagachanthan ${ }^{2}$, Dr. K.S. Sridhar ${ }^{3}$, Dr. M. Kalidasan ${ }^{4}$, S. Malar \\ \& M. Manogari ${ }^{6}$
}

${ }^{1}$ Associate Professor, Department of Physical Education and Health Sciences, Alagappa University, Karaikudi. ${ }^{2}$ Director of Physical Education, VIT, Vellore, Tamilnadu. ${ }^{3}$ Director of Physical Education, Pachayappas College, Chennai, Tamilnadu. ${ }^{4}$ Physical Education Teacher, Government Boys Higher Secondary School, Manamelkudi, Pudukkottai. ${ }^{5}$ (UGC-NET-SRF), Ph.D Scholar, Department of Physical Education and Health Sciences, Alagappa University, Karaikudi. ${ }^{6}$ M.Phil Scholar, Department of Physical Education and Health Sciences, Alagappa University, Karaikudi.

DOI: http://doi.org/10.38177/ajast.2021.5105

Copyright: @2021 Dr.Maniazhagu Dharuman et al. This is an open access article distributed under the terms of the Creative Commons Attribution License, which permits unrestricted use, distribution, and reproduction in any medium, provided the original author and source are credited.

\section{ABSTRACT}

The purpose of the present study was to find out the effects of circuit training and battle rope training on upper body muscular endurance of school girls. To achieve the purpose of the study thirty school girls from M. Deivanai Achi Government Girls Higher Secondary School, Paganeri, Sivaganga District, Tamilnadu were selected as subjects. The selected subjects' age ranged from 11 to 13 years. The selected subjects were equally divided into three groups, i.e. two experimental groups and one control group. The experimental group-1 was allotted to circuit training (CT); the experimental group-2 was allotted for battle rope training (BRT) and group-3 acted as control group (CG). The upper body muscular endurance was chosen as a dependent variable; it was tested by modified pushups. The test was taken before and after the training interventions. Analysis of covariance (ANCOVA) was used to analyze the significant difference, if any among the groups. In order to find out superiority effect among the groups, the Scheff's Post Hoc test was used. The level of significance was 0.05. After the six weeks training interventions the experimental groups improved the capacity of upper body muscular endurance. The best improvement was noticed in battle rope training.

\section{Introduction}

Now a day's fitness is considered as most important health indicators in childhood. The concept of physical fitness has since evolved to include morphological and metabolic components. (Sutha, Maniazhagu, 2019) During the early stages of strength training, especially with entry-level athlete almost any strength training method or program will result in strength development to some degree (Maniazhagu, Malar, Manogari, 2019) Children and young people are now recommended to take part in at least 60 minutes of moderate to vigorous physical activity daily to promote and protect healthy heart function, increase bone and muscle strength, improve mood and lower the risk of depression and reduce the risks of obesity, osteoporosis and diabetes (Malar, Maniazhagu, 2020) Different training methods have been commonly used to improve physical fitness and related standards of performance of athletes. (Maniazhagu, 2010) During recent years, the circuit training program is a form of exercise that has become widely used. (Davis et al, 2011) Circuit training is often erroneously portrayed as an intensive and stressful form of exercise, with a drill sergeant type in the middle of a circuit bellowing orders at weary recruits. Circuit training is a very versatile and adaptable mode of training that requires the performance of a series of carefully selected exercises. The use of resistance bands and cords as a form of exercise is becoming increasingly popular. (Lawrence, Hope, 2015) The intensity and vigor of circuit training are indeed challenging and enjoyable to the performer. This system produces positive changes in motor performance, general fitness, muscular power endurance and speed. (D. Maniazhagu, C.Robert Alexander and Sukumar Sha, 2011)

The circuit training effectively reduces the time devoted to training while allowing an adequate training volume to be achieved (Alcaraz Ramon et al. 2008). Moreover, it permits a greater motor engagement time (Lozano et al., 


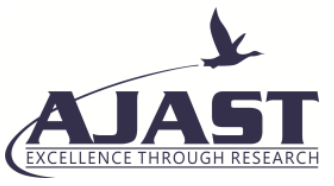

Asian Journal of Applied Science and Technology (AJAST)

Volume 5, Issue 1, Pages 39-43, January-March 2021

2009). Strength training is a long-term intention. Trainees do not achieve the peak performance immediately after the four to six weeks of training. But relatively during the competitive phase, which is months away from the anatomical adaptation phase. (Sridhar, Maniazhagu, 2018)

\section{Methodology}

To achieve the purpose of the study thirty school girls from M. Deivanai Achi Government Girls Higher Secondary School, Paganeri, Sivaganga District, Tamilnadu were selected as subjects. The selected subjects' age ranged from 11 to 13 years. The selected subjects were equally divided into three groups, i.e. two experimental groups and one control group. The experimental group-1 was allotted to circuit training (CT); the experimental group-2 was allotted for battle rope training (BRT) and group-3 acted as control group (CG). The upper body muscular endurance was chosen as a dependent variable; it was tested by modified pushups. The test was taken before and after the training interventions. The training approach was taken for the period of six weeks, five days in a week.

\section{Results}

Table-I: The Results of Analysis of Covariance on Upper Body

Muscular Endurance of Different Groups

(Scores in Numbers)

\begin{tabular}{|c|c|c|c|c|c|c|c|c|c|}
\hline \multicolumn{2}{|c|}{ Test Conditions } & Ex-1 & Ex-2 & Gr-3 & SV & SS & Df & MS & ' $\mathbf{F}$ ' \\
\hline \multirow{2}{*}{ Pre test } & Mean & 14.4 & 14.4 & 14.0 & B & 1.06 & 2 & 0.53 & \multirow{2}{*}{0.85} \\
\hline & S.D. & 0.69 & 0.69 & 0.94 & W & 16.8 & 27 & 0.62 & \\
\hline \multirow{2}{*}{ Post test } & Mean & 16.4 & 18.8 & 13.7 & B & 13.0 & 2 & 65.1 & \multirow{2}{*}{$79.53 *$} \\
\hline & S.D. & 0.51 & 0.91 & 1.15 & W & 2.2 & 27 & 0.81 & \\
\hline \multirow{3}{*}{$\begin{array}{l}\text { Adjusted } \\
\text { Post test }\end{array}$} & \multirow{3}{*}{ Mean } & \multirow{3}{*}{16.34} & \multirow{3}{*}{18.74} & \multirow{3}{*}{13.81} & B & 115.9 & 2 & 57.97 & \multirow{3}{*}{$79.27 *$} \\
\hline & & & & & & & & & \\
\hline & & & & & W & 19.04 & 26 & 0.73 & \\
\hline
\end{tabular}

*Significant at .05 level of confidence. The required table values was $3.35 \& 3.37$ with the df of 2 and 27,2 and 26 .

\section{Results of Upper Body Muscular Endurance}

The pre test mean and standard deviation on upper body muscular endurance scores G1, G2 and G3 were $14.4 \pm 0.69,14.4 \pm 0.69$ and $14.0 \pm 0.94$ respectively. The obtained pre test $F$ value of 0.85 was lesser than the required table $\mathrm{F}$ value 3.35 . Hence the pre test means value of circuit training; battle rope training and control group on upper body muscular endurance before start of the respective treatments were found to be insignificant at 0.05 level of 
confidence for the degrees of freedom 2 and 27. Thus this analysis confirmed that the random assignment of subjects into three groups were successful.

The post test mean and standard deviation on upper body muscular endurance of G1, G2 and G3 were 16.4 \pm 0.51 , $18.8 \pm 0.91$ and $13.7 \pm 1.15$ respectively. The obtained post test $F$ value of 79.53 was higher than the required table $F$ value of 3.35. Hence the post test means value of circuit training and battle rope training on upper body muscular endurance were found to be significant at 0.05 level of confidence for the degrees of freedom 2 and 27.

The results proved that the selected training interventions circuit training and battle rope training was produced significant improvement rather than the control group of the sample populations.

The adjusted post test means on upper body muscular endurance scores of G1, G2 and G3 were 16.34, 18.74 and 13.81 respectively. The obtained adjusted post test $F$ value of 79.27 was higher than the required table $F$ value of 3.37. Hence the adjusted post test means value of circuit training and battle rope training on upper body muscular endurance were found to be significant at 0.05 level of confidence for the degrees of freedom 2 and 26.

The results confirm that the two training interventions namely circuit training and battle rope training on upper body muscular endurance were produced significant difference among the groups.

The Scheff's post hoc test was overseen to find the superiority effects among the groups. It is shown in table-I (a).

Table-I (a):

The Results of Scheffe's Post Hoc Test Mean Differences on Upper Body Muscular Endurance among Three Groups (Scores in Numbers)

\begin{tabular}{|c|c|c|c|c|}
\hline Ex-1 & Ex-2 & Gr-3 & $\begin{array}{c}\text { Mean } \\
\text { Differences }\end{array}$ & $\begin{array}{c}\text { Confidence Interval } \\
\text { Value }\end{array}$ \\
\hline $\mathbf{1 6 . 3 4}$ & 18.74 & CG & $2.4^{*}$ & 1.21 \\
\hline $\mathbf{1 6 . 3 4}$ & & 13.81 & $2.52^{*}$ & 1.21 \\
\hline & 18.74 & 13.81 & $4.92^{*}$ & 1.21 \\
\hline
\end{tabular}

* Significant at .05 level of confidence.

\section{Result of Scheff's Post Hoc test on Upper Body Muscular Endurance}

Table I (a) shows the paired mean differences of selected groups on upper body muscular endurance.

The paired mean differences between circuit training and battle rope training, circuit training and control group, battle rope training and control group were 2.4, 2.52, and 4.92 respectively. These values are higher than the confidential interval value of 1.21 . Hence, it is clear that the pair wise comparisons of above groups were produced significantly different effect on upper body muscular endurance.

The adjusted post test mean deference of experimental and control group value graphically signified in the figure 1. 


\section{FIGURE 1}

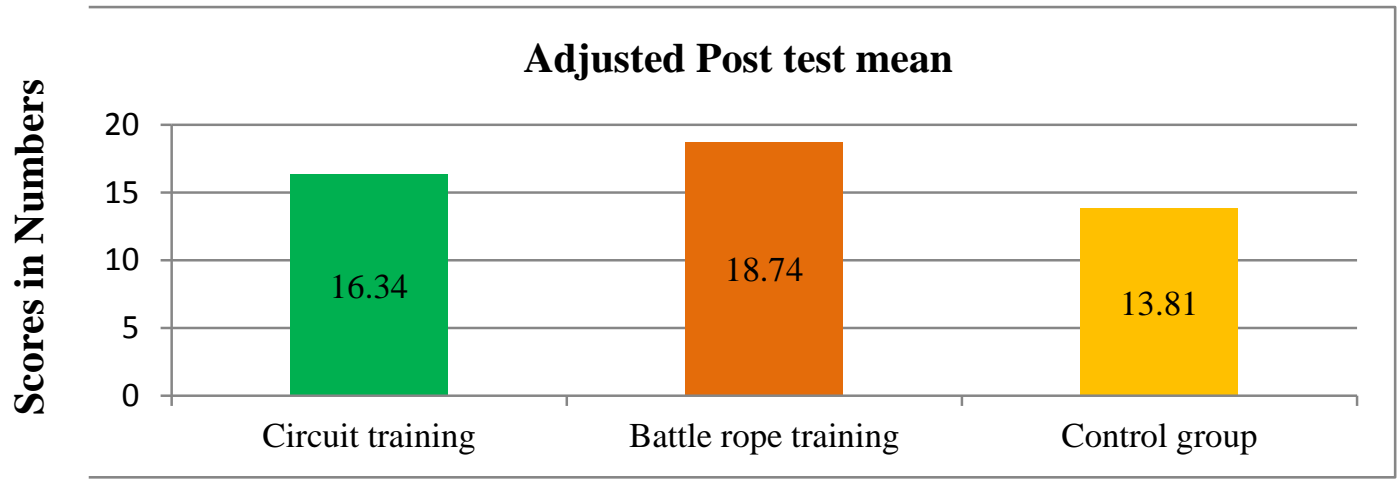

\section{Discussion on findings}

Maniazhagu (2019) found that the concurrent strength and endurance training improved the capacity of muscular endurance. Sonchan, Pratoom Moungmee, Sootmongkol (2017) found that the circuit training is an effective way to improve both aerobic and anaerobic performance that forms the foundation of health related physical fitness. Kumar V.Senthil, Maniazhagu (2014) found that muscular endurance was improved due to the effects of circuit resistance training. Sridhar and Maniazhagu (2018) conducted a study to find the explosive strength and strength endurance based circuit training on muscular endurance. They found that the capacity of muscular endurance was highly favored in strength endurance based circuit training than explosive strength based circuit training. Biju Peter, Maniazhagu (2018) found that low and moderate intensities of plyometric training have produced similar effect on muscular endurance. Maniazhagu, Sukumar and Selvaraj (2011) found that the speed, leg explosive power and muscular endurance were significantly improved due to the influence of strength training

\section{Conclusion}

After the six weeks of circuit and battle rope training have produced greater effect on upper body muscular endurance. The superior effect was found in battle rope training than the circuit training. The control group did not show any significant improvement.

\section{Acknowledgement}

Dr.D.Maniazhagu thank for the financial support of MHRD-UGC, RUSA-Phase 2.0 grant No.F, 24-5/2014-U, Policy (TN Multi-Gen), Dept. of. Edn. Government of India, dt 09.10.2018

\footnotetext{
References

Alcaraz Ramon PE, Sanchez-Lorente J, Blazevich AJ. Physical performance and cardiovascular responses to an acute bout of heavy resistance circuit training versus traditional strength training. J Str Cond Res, 2008 22: 667-671 Biju Peter, Maniazhagu, (2018), "Effect of low and moderate intensities of aquatic plyometric training combined with yogic practices on muscular endurance of junior athletes", International journal of physical education sports management and yogic science, Vol.8/No.3, 1-9.

D. Maniazhagu, C.Robert Alexander and Sukumar Sha, (2011), "Effects of aerobic training and circuit training on muscular strength and muscular endurance", International Journal of Physical Education, 4(2); 132-134.
} 
Debbie Lawrence, Richard (Bob) Hope (2015). The Complete Guide to Circuit Training. A\&amp;C Black Publisher.

J. N. Davis, L. E. Gyllenhammer, A. A.Vanni, M. Meija, A. Tung, E. T. Schroeder, D. Spruijt-Metz, and M. I. Goran, "Startup circuit training program reduces metabolic risk in Latino adolescents," Medicine \& Science in Sport \& Exercise. April 2011, pp. 2195-2203.

Kumar V.Senthil, Maniazhagu (2014). "Effects of circuit resistance training on selected motor fitness variables", International Journal of Physical Education Sports Management and Yogic Sciences, 4(1): 37-40.

Lozano L, Viciana J, Martínez JC, Cocca A, Jiménez R. Influence of classroom environment and motor engagement time. Rev Mex Psicol, 2009; 26: 675-676.

Malar, Maniazhagu (2020). "Effects of integrative neuromuscular training combined with yoga and stretching exercises on abdominal strength endurance of primary school children", Indian Journal of Public health research and development, 11(03): 899-903.

Dr.D.Maniazhagu (2010). "Effects of two modes of resistance training on speed leg explosive power and anaerobic power of college men students", Indian Journal for research in Physical Education and sports sciences, October 2010-March 2011, 31-34.

Maniazhagu (2019). "Effects of concurrent strength and endurance training on endurance". International journal of physical education sports management and yogic sciences, 9(4): 14-24.

Maniazhagu, D., Saha, Sukumar and Selvaraj, P. (2011). Effects of strength training on speed leg explosive power and muscular endurance of college men students. Internat. J. Phy. Edu., 4 (1) : 191-193.

Maniazhagu, Malar, Manogari, (2019). "Effects of circuit training and battle rope training on speed of school girls", Asian Journal of Applied Science and Technology, 3(3); 66-72.

Sridhar and Maniazhagu (2018). "Effects of explosive strength and strength endurance based circuit training on muscular endurance” International J. of Physical Education Sports Management and Yogic Sciences, 8(4): 8-16.

K.Sudha, Maniazhagu (2019). "Effects of circuit training combined with different neuromuscular activities on muscular endurance and body composition of school girls". Indian Journal of Public Health Research \& Development, Vol. 10, No. 12, PP. 1329-1333.

Wirat Sonchan, Pratoom Moungmee, Anek Sootmongkol (2017). "The Effects of a Circuit Training Program on Muscle Strength, Agility, Anaerobic Performance and Cardiovascular Endurance” International Journal of Sport and Health Sciences, Vol: 11, No: 4, 2017. 